\section{Society prospects: on one hand . . .}

\section{Brian Whitton}

FEMS Microbiology Ecology. Editor-inchief H. Veldkamp. Elsevier, 6/yr. Dfl. 275, $\$ 111$ (institutional); Dfl. 136, \$55 (individual).

Microbial ecology is one of the fastergrowing branches of microbiology. Up to quite recently, however, most papers on the subject were scattered through the mainstream microbiology or environmental journals, some of which welcomed them and some of which accepted them only with reluctance, and were also to be found in a variety of symposium-type books. But there is an increasing tendency to publish relevant work in journals largely or entirely devoted to the subject, and FEMS Microbiology Ecology is a recent addition to these.

The stated aims are to deal "with fundamental aspects of the ecology of microorganisms in natural soil, air or aquatic environments, or in artificial or managed environments". So far, the journal has done well in satisfying these interests the articles have covered a wide range of heterotrophic and autotrophic organisms

\section{PHARMACOLOGY/ IMMUNOLOGY}

IBM PC,XT,AT; APPLE II, $\mathrm{II+}$, lle \& VAX-VMS. Laboratory software for use in research labs. Software products include those for analysis of ligand binding, enzyme kinetics, breast tumor estrogen and progesterone receptor content, and multiple exponential curve analysis. Products are menu driven and include external documentation.

Send for catalog. Specify computer.

Lundon Software, Inc. P.O. Box 21820 Cleveland, Ohio 44121 216-371-6220 from many different types of environment, and collectively demonstrate that microbial ecology has become a truly quantitative branch of science. Most papers have come from Europe, with a relatively large proportion from The Netherlands, partly no doubt because of contacts with the editor but also because microbial ecology is better represented there than elsewhere in Europe.

Publication is rapid, about three to four months from the date the paper is accepted, 50 free reprints are offered and there are no page charges. Editing, general lay-out and figures are all of a high standard, though the FEMS system of using one series of volume numbers for their three journals is likely to cause confusion in the library. For instance the two most recent FEMS Microbiology Ecology volumes are 31 (1985) and 38 (1986): during 1986, volumes 33-37 are FEMS Microbiology and 39 is FEMS Microbiology Reviews.

The quality of the journal is such that it deserves to succeed. The only doubt is

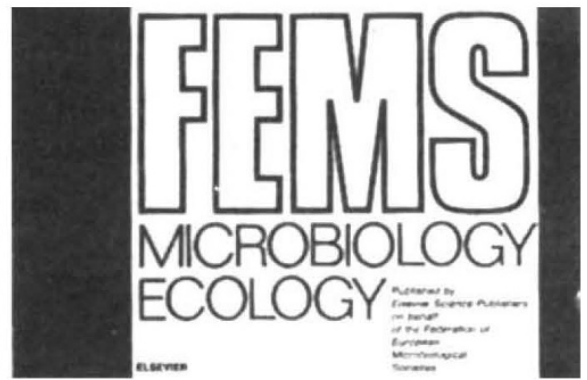

that a publication serving such a broad field, and with numerous contributors competing to get high-quality papers accepted, probably needs to issue much more than one volume each year if it is to become a prestige title. My guess is that the journal will eventually either have to expand, in order to compete with the American Society for Microbiology's $\mathrm{Ap}$ plied and Environmental Microbiology, or select some aspect on which to specialize. I hope it proves to be the former.

Brian Whitton is a Reader in the Department of Botany, University of Durham, Durham DHI 3LE, UK.

\section{. . . but on the other}

\section{David H. Boxer}

FEMS Microbiology Reviews. Editor-inchief G. Gottschalk. Elsevier. 4/yr. Dfl. 275, $\$ 111$ (institutional); Dfl. 149, \$60 (individual).

FEMS Microbiology Reviews was launched by the Federation of European Microbiological Societies with the intention of providing profound and readable reviews of progressing areas of microbiology. The appearance of a European-based review journal will be widely welcomed, but this publication does not seem to be destined to become an authoritative alternative to the American Society for Microbiology's Microbiological Reviews.

The journal is well laid out in the usual FEMS format, but would benefit from clearer illustrations. The articles themselves are quite readable with most, but not all, carrying a useful summary. I found the quality rather variable, however. Some articles are genuinely authoritative and review topics of wide importance, but many others are far too short and insubstantial. For example, one of them is a mere four pages long, and over a third are of eight pages or less. Another contains 15 figures and one table of one of the authors' unpublished observations which surely ought to have been published in the primary literature rather than a review journal. It is difficult to equate brevity with profundity, and many of the shorter articles may have found a better home in the more popular Microbiological Sciences.
Despite the short time, usually a few weeks, taken for an editorial decision, the publication as a single issue of the last two numbers of the most recent volume clearly led to long publishing delays, in one case some ten months. But few journals can claim to correct printing errors as fully as this one, since in one case it republished a complete article in order to set matters right!

A comparison with the contemporary volume (49) of ASM's Microbiological Reviews revealed that the ASM journal published 20 articles each citing, on average, over 200 publications, to the FEMS journal's 16 articles whose average bibliography lists just over a 100 references. At the institutional price, the FEMS journal is about three times more expensive per cited publication and the comparison is even less favourable at the personal subscriber level. I doubt whether many individuals will consider taking out a personal subscription, and I cannot see its justifying a place in the library unless the quality of its articles becomes more uniformly high.

David H. Boxer is a Senior Lecturer in the Department of Biochemistry, Medical Sciences Institute, University of Dundee, Dundee DDI $4 H N$, UK.

\section{Journal prices}

Details of editors and frequency of publication, and the subscription rates appearing at the top of each review, are given in most instances for 1987. This information is not complete in all cases; an individual rate may be available, for example, or there may be an additional charge for air-mail delivery. Readers interested in a particular journal should therefore check prices with the publisher before subscribing. 